IIIIIIIIIIIIIIIIIIIIIIIIIIIIIIIIIIII

Original Article

IIIIIIIIIIIIIIIIIIIIIIIIIIIIIIIIIII

\title{
Synergistic effects of adjuvant A-134 on the herbicidal effects of glyphosate
}

\author{
Youwu HaO, ${ }^{1, \dagger}$ Yang Zhang, ${ }^{1, \dagger}$ Wenping Xu, ${ }^{1}$ Jufang $\mathrm{GAO}^{2}$ and Liming TAO ${ }^{1, *}$ \\ ${ }^{1}$ Shanghai Key Laboratory of Chemical Biology, School of Pharmacy, East China University of Science and Technology, Shanghai 200237, China \\ ${ }^{2}$ College of Life and Environmental Sciences, Shanghai Normal University, Shanghai 200234, China
}

(Received April 11, 2019; Accepted August 11, 2019)

\begin{abstract}
Undesirable side effects on ecosystems and strong selection for weed resistance demand an increase in the efficacy and a reduction in the dosage of glyphosate herbicide used. The synergistic effect of tank-mixed adjuvant $\mathrm{KAO}^{\circledR} \mathrm{A}-134$ (A-134) on the postemergence activity of the commercial glyphosate formulation Roundup ${ }^{\circledR}$ (RDP) against crabgrass (Digitaria sanguinalis) was detected. Field study also showed that A-134 can increase the herbicidal effect of RDP. Meanwhile, A-134 concentration-dependently decreased the surface tension and increased the spreading area of RDP, causing faster penetration and improved uptake of glyphosate into crabgrass. Moreover, the tank mix with A-134 also increased the adhesion of spray droplets of glyphosate isopropylamine salt (GP) to the leaf surface after rainfall treatment, thus maintaining its herbicidal effect. Data suggested the necessity of using these synergistic properties of A-134 to reduce environmental exposure and glyphosate resistance selection.
\end{abstract}

Keywords: adjuvant A-134, synergistic effect, glyphosate, crabgrass, rain fastness.

\section{Introduction}

Herbicides currently provide not only a simple and cost-effective way of managing weeds but also a positive means of freeing up labor and improving crop quality. ${ }^{1)}$ Since the use of pesticides in agriculture inevitably leads to the exposure of humans and other non-targeted organisms, undesirable side effects on communities or on ecosystems as a whole make it essential to reduce the dosage used and increase the efficacy and long-term control of herbicides. ${ }^{2,3)}$

Herbicides must overcome a variety of barriers to their entry into plants in order to be effective. The addition of adjuvants to a herbicide formulation or tank mix can promote more even coverage of plant surfaces by the herbicide and increase the formulation's penetration through the cuticular wax, cell walls, and/ or stomatal openings. ${ }^{4,5)}$ Organosilicone surfactants can reduce the surface tension of the spray solution, promote the infiltration of the herbicide into stomata, and increase the rate of droplet spread over the leaf surface. ${ }^{6,7)}$ The addition of the adjuvants At-

\footnotetext{
* To whom correspondence should be addressed.

E-mail: taolm@ecust.edu.cn

$\dagger$ These authors contributed equally to this work.

Published online October 8, 2019
}

(c) BY-NC-ND (c) Pesticide Science Society of Japan 2019. This is an open access article distributed under the Creative Commons AttributionNonCommercial-NoDerivatives 4.0 International (CC BY-NC-ND 4.0) License (https://creativecommons.org/licenses/by-nc-nd/4.0/) erbane at 0.5 and $0.25 \% \mathrm{v} / \mathrm{v}$ and Silwet L 77 at 0.1 and $0.05 \% \mathrm{v} / \mathrm{v}$ can increase the absorption of glyphosate and reduce the dose of glyphosate by more than $50 \%$ as compared with glyphosate used without adjuvants. ${ }^{8)}$ The pervious experiments has already showed that surfactants that produce smaller spreading areas on plant foliage usually have a limited effect on enhancing the permeability of the cuticle or cell membrane. ${ }^{9)}$ In the wake of the potential toxicity of POEA (polyethoxylated tallow amine) in Roundup $^{\circledR}$ (RDP), the most widely used herbicide worldwide, to humans, animals, and the environment, ${ }^{10)}$ a proper, healthoriented regulatory system has garnered increasing attention regarding the synergistic effects of herbicide mixtures.

Glyphosate is a systemic hydrophilic herbicide that has nonselective, broad-spectrum effects on many annual grasses and broadleaf weeds post emergently. ${ }^{11)}$ Glyphosate-based herbicides in different formulations are the most widely used across the world, and this widespread use of glyphosate greatly increases the chances that it will be ingested by humans and farm animals. ${ }^{9)}$ Improved foliar uptake may reduce the usage dose and increase the efficacy of glyphosate. KAO A-134 (A-134) is an environmental friendly new botanical adjuvant innovated by Japan's Kao Corporation. Experiments in the present study were conducted to: a) identify the influence of A-134 on the surface tension and spreading area; b) compare the post-emergence activity with A-134; c) determine rain-leaching tolerance in the presence of A-134. 


\section{Materials and Methods}

\section{Chemicals}

$\mathrm{KAO}^{\circledR}$ adjutant A-134 was commercially provided by EcoInnovation Research, Kao Corporation, Japan. Forty-one percent glyphosate isopropylamine salt AS (Roundup ${ }^{\circledR}$, Abs. RDP) purchased from Monsanto Company (St. Louis, MO, USA) and glyphosate isopropylamine salt (GP, $\geq 95 \%$ ) obtained from Hanfu Biochemical Pharmaceutical Co., Ltd. (Weihai, China) were used in experiments.

\section{Plants}

Crabgrass (Digitaria sanguinalis L.) and barnyard grass (Echinochloa crusgalli L.) plants were grown from seed in a controlled environment $\left(25 / 16^{\circ} \mathrm{C} \pm 2^{\circ} \mathrm{C}\right.$ day/night temperature and $70 \pm 5 \%$ relative humidity). Experiments were performed when the crabgrass or barnyard grass reached the 3-3.5 leaf growth stage.

\section{Assays of post-emergence activity in the greenhouse}

The effects of RDP applied post emergently were tested on crabgrass at the 3-3.5 leaf growth stage in according with the reported assays. RDP was diluted with distilled water and applied to the foliage of the seedlings at concentrations of 100, 200,300, 400,500 , or $600 \mathrm{~g}$ a.i./ha. In a parallel test, adjuvant A-134 was tank mixed with each dilution of RDP, and the concentration of A-134 in the mixture was set at $0.025 \%, 0.05 \%, 0.1 \%$, or $0.2 \%$. The tank mix was applied as described above. The diluted RDP and the mixtures were applied using a laboratory sprayer with a flat fan nozzle at a water volume of $450 \mathrm{~L} / \mathrm{ha}$. Treatments were replicated four times and arranged in completely random blocks within the greenhouse. Two weeks after treatment, the shoot portion of the crabgrass was collected. The efficaies of the diluted RDP and the mixtures were measured from the fresh weight of the shoot portions of the crabgrass. The $\%$ inhibition was then calculated using formula (1): [1-(fresh weight in the treatment/ fresh weight in the control) $] \times 100$. The half efficacy concentration $\left(\mathrm{EC}_{50}\right)$ was calculated by probit analysis based on the regression percent inhibition and the log of test concentration of the diluted RDP and the mixtures. The relative toxic index was calculated using formula (2): $\left(\mathrm{EC}_{50}\right.$ of the diluted $\mathrm{RDP} / \mathrm{EC}_{50}$ of the mixture with A-134) $\times 100$.

\section{Field study}

Field studies were conducted in 2017 at the National South Pesticide Discovery Center (Shanghai) on an indigenous weed population. Every treatment involved plots $(1.2 \mathrm{~m}$ long $\times 1.2 \mathrm{~m}$ wide). RDP was diluted with distilled water and applied to the foliage of the seedlings at concentrations of 500 and $700 \mathrm{~g}$ a.i./ ha. In a parallel test, adjuvant A-134 was tank mixed with each dilution of RDP, and the concentration of A-134 in the mixture was set at $0.05 \%, 0.1 \%$, or $0.2 \%$. The tank mix was applied as described above. The same concentrations of RDP that contained no A-134 were used as the control. Diluted RDP and the mixtures were applied using a laboratory sprayer with a flat fan nozzle at a water volume of $450 \mathrm{~L} / \mathrm{ha}$. The formulation was sprayed on June 14 and July 8, 2017 when the majority of weeds were $15-20 \mathrm{~cm}$ tall, and the weed density was $80-90 \%$. Tractor-mounted boom sprayers applied the formulations at a speed of $4.8 \mathrm{~km} / \mathrm{hr}^{12}$ ) Weed species present in 2017 were tendon grass (Eleusine indica L.), perennial ryegrass (Lolium perenne L.), and triangular grass (Cyperus iria L.). Visual mortality data were recorded periodically up to fourteen days after spraying on a $0-100$ scale, where $0=$ no effect (healthy, green leaves), and $100=$ complete mortality (withered, yellow leaves). ${ }^{13)}$

\section{Rainfastness test}

The trials in the greenhouse were carried out on crabgrass and barnyard grass at 3-3.5 leaf growth stage in accordance with the previous method. ${ }^{14)}$ GP was diluted with distilled water and applied to the foliage at a concentration of $37.5,50$, or $75 \mathrm{~g}$ a.i./ha for crabgrass seedlings and 55.5, 75, and $111.0 \mathrm{~g}$ a.i./ha for barnyard grass seedlings. A tank mix of the diluted GP and adjuvant A-134 at a concentration of $0.1 \%$ or $0.2 \%$ was used as a standard treatment. The same amount of GP without A-134 was used as the control. After treatment for $1 \mathrm{hr}$, a rainfall simulation was made using a backpack $\mathrm{CO} 2$ sprayer (30 psi) with a Lurmark nozzle. The applied water volume was $4.5 \mathrm{~mm}$ per hour, the application pressure was $0.2 \mathrm{MPa}$, and the total amount of water used during the experiment was $74 \mathrm{~L} / \mathrm{ha}$. Two weeks after treatment, the shoot portions of the grasses were weighed. The $\%$ inhibition of the fresh weight was then calculated using the above formula (1).

\section{Determination of surface tension}

The effect of adjuvant A-134 on the surface tension of RDP was examined using the previous method. ${ }^{15)} \mathrm{RDP}$ at a concentration of $4000 \mathrm{mg} / \mathrm{L}$ was mixed with $0.05 \%, 0.1 \%, 0.2 \%$, and $0.4 \%$ A-134 aqueous solution at a $1: 1$ ratio $(\mathrm{v} / \mathrm{v})$. The same volume of distilled water as for A-134 was used as the control. The surface tensions of the mixtures were determined by using a TX500C spinning drop interfacial tensiometer (USA KINO Industry Co., Boston, MA, USA). The temperature of the test mixture was set at $25 \pm 0.5^{\circ} \mathrm{C}$. Each mixture was measured three times and the treatment replicated.

\section{Determination of the spreading area}

Droplets $(5 \mu \mathrm{L})$ of RDP $(4000 \mathrm{mg} / \mathrm{L})$ mixed with $0.025,0.05,0.1$, or $0.2 \% \mathrm{~A}-134(1: 1, \mathrm{v} / \mathrm{v})$ were applied by a microsyringe to the wax surface. The same volume of distilled water as for A-134 was used as the control. After standing for $5 \mathrm{~min}$, the diameter of the droplet spreading area was determined under a microscope. At least 10 replicates on separate droplets were used for each treatment.

\section{Uptake assessment}

Droplets $(10 \mu \mathrm{L})$ of the mixture $(1: 1, \mathrm{v} / \mathrm{v})$ of $4000 \mathrm{mg} / \mathrm{L}$ RDP and $0.1 \%$ A- 134 were applied by a microsyringe to the central region of the adaxial surface of the fully expanded leaf on crab- 
Table 1. Control efficacy (the $\%$ inhibition of the fresh weight) and median efficient concentration $\left(\mathrm{EC}_{50}\right)$ of $\mathrm{RDP}$ after mixed with water and $0.025,0.05$, 0.1 , or $0.2 \% \mathrm{KAO}^{\circledR}$ adjuvant A-134 against Digitaria sanguinalis in the greenhouse

\begin{tabular}{|c|c|c|c|c|c|}
\hline & \multicolumn{5}{|c|}{ Conc. of A-134 (\%) } \\
\hline & Water & 0.025 & 0.05 & 0.1 & 0.2 \\
\hline \multicolumn{6}{|c|}{ Dosage of Roundup ${ }^{\circledR}$ (ga.i./ha) } \\
\hline 100 & $-0.9 \pm 3.5 b^{b)}$ & $28.0 \pm 3.3 \mathrm{a}$ & $26.3 \pm 2.9 \mathrm{a}$ & $33.9 \pm 3.0 \mathrm{a}$ & $42.9 \pm 3.4 \mathrm{a}$ \\
\hline 200 & $29.8 \pm 3.9 c$ & $36.8 \pm 3.6 b c$ & $42.8 \pm 3.1 b$ & $51.1 \pm 3.0 \mathrm{~b}$ & $62.6 \pm 5.8 \mathrm{a}$ \\
\hline 300 & $29.5 \pm 5.7 c$ & $50.6 \pm 4.9 b$ & $50.2 \pm 4.2 b$ & $67.8 \pm 2.5 \mathrm{a}$ & $70.2 \pm 4.7 \mathrm{a}$ \\
\hline 400 & $71.7 \pm 1.2$ & $69.9 \pm 1.9 b$ & $70.6 \pm 3.4 b$ & $70.4 \pm 1.7 \mathrm{~b}$ & $79.2 \pm 2.8 \mathrm{a}$ \\
\hline 500 & $79.4 \pm 2.2 b$ & $79.6 \pm 1.0 \mathrm{~b}$ & $83.2 \pm 1.6 \mathrm{a}$ & $85.8 \pm 1.4 \mathrm{a}$ & $83.7 \pm 1.7 \mathrm{a}$ \\
\hline 600 & $82.6 \pm 2.5 a$ & $83.5 \pm 2.9 \mathrm{a}$ & $81.9 \pm 2.7 \mathrm{a}$ & $83.3 \pm 2.7 a$ & $83.0 \pm 2.1 \mathrm{a}$ \\
\hline $\mathrm{ED}_{50}(\mathrm{mg} / \mathrm{L})$ & $366.8 \mathrm{a}$ & $233.5 b$ & $224.9 \mathrm{bc}$ & $175.8 \mathrm{c}$ & $175.8 \mathrm{c}$ \\
\hline R.T.I. ${ }^{a}$ & 100.0 & 157.1 & 163.1 & 208.7 & 260.5 \\
\hline
\end{tabular}

a) R.T.I. was the abbreviation of the relative toxic index. $\left.{ }^{b}\right)$ Means followed by the same letter in each column were not significantly different $(p<0.05$, LSD test).

grass plants. The same volume of distilled water as for $0.1 \%$ A-134 was used as the control. Every treatment contained three replicate plants (one leaf per plant) and all plants were kept under constant growing conditions $\left(20^{\circ} \mathrm{C} ; 70 \% \mathrm{RH}\right)$ for $10 \mathrm{~min}$ the uptake period. The treated leaves were excised and washed three times with $1 \mathrm{~mL}$ distilled water. The content of glyphosate in the washings was determined by high-performance liquid chromatography using methanol/water (PBS, PH2) (5:95) as the mobile phase, an Agilent ZORBAX SAX ion exchange column, $30^{\circ} \mathrm{C}$ column temperature, and $195 \mathrm{~nm}$ wavelength detection. Glyphosate uptake was calculated as the initial concentration minus the residual concentration in the water.

\section{Data analysis}

All data were presented as the mean \pm S.E. and subjected to analysis of variance (ANOVA) using SPSS version 17.0. Mean separations among treatments were compared using the least significant difference (LSD) test. The level of significant difference $(P)$ was set at 0.05 .

\section{Results}

\section{Bioefficacy study}

1.1. Synergistic effect of A-134 on the post-emergence activity of RDP in the greenhouse

After spraying for 14 days, RDP at concentrations greater than $400 \mathrm{~g}$ a.i./ha killed crabgrass completely. With RDP treatments at concentrations lower than $300 \mathrm{~g}$ a.i./ha, A-134 strongly improved the control efficacy of RDP against crabgrass in a concentrationdependent manner (Table 1). The addition of A-134 also caused a corresponding decrease of the $\mathrm{EC}_{50}$ values of RDP, indicating that the increased toxicity of RDP was positively correlated to the concentration of A-134. The relative toxicity index showed that the toxicity of RDP was increased 2.6 times in the presence of $0.2 \%(\mathrm{v} / \mathrm{v})$ A-134 as compared to the control.

\subsection{Field study}

The results of the first field experiment, on June 14, 2017, are shown in Figure 1a, and the results of the second field experi- ment, on July 8, 2017, are shown in Figure 1b. The results of both experiments showed that glyphosate formulation activity varied significantly when mixed with A-134. In the first field experiment, under a condition with no rainfall, GP at concentrations of 500 and $700 \mathrm{~g}$ a.i./ha showed control efficacies of 47.3 and $72.3 \%$ against weeds, respectively. After tank mixing with
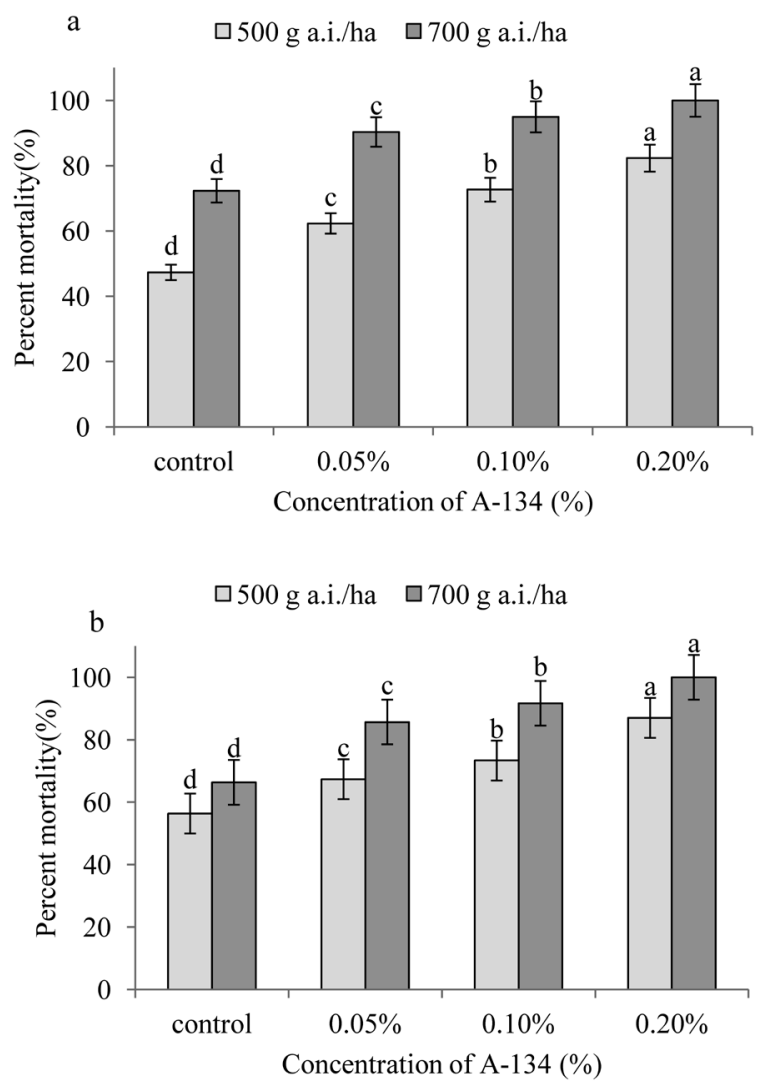

Fig. 1. Percent mortality on weeds. Weeds treated with RDP (tank-mixed with $0,0.05,0.1$ and $0.2 \%(\mathrm{v} / \mathrm{v})$ A-134, respectively) for 14 days in 2 concentration (500 and $700 \mathrm{~g}$ a.i./ha) on June 14, 2017 (a) and July 8, 2017 (b). 



Fig. 2. Effect of rainfall on reduces the control efficacy of GP and $\mathrm{GP}+\mathrm{A}-134$ against $D$. sanguinalis (a) and E. crusgalli (b), respectively. Data were statistical values of 2 sets with 3 parallel replicates. Means followed by the same letter were not significantly different ( $p<0.05$, LSD test).

$0.05 \%, 0.1 \%$, and $0.2 \%(\mathrm{v} / \mathrm{v}) \mathrm{A}-134$, the control efficacies of $675 \mathrm{~g}$ a.i./ha GP increased to $62.3,72.7$, and $82.3 \%$, respectively, and those of $700 \mathrm{~g}$ a.i./acre GP were enhanced to $90.3,95.0$ and $100.0 \%$, respectively. In the second field experiment, under a condition with no rainfall, GP at concentrations of 500 and $700 \mathrm{~g}$ a.i./ha showed control efficacies of 56.3 and $66.3 \%$ against weeds, respectively. After tank mixing with $0.05 \%, 0.1 \%$, and $0.2 \%(\mathrm{v} / \mathrm{v}) \mathrm{A}-134$, the control efficacies of $500 \mathrm{~g}$ a.i./ha GP were increased to $67.3,73.3$, and $87.0 \%$, respectively, and those of 700 ga.i./acre GP were enhanced to $85.7,91.7$ and $100.0 \%$, respectively.

\subsection{Influence of $A-134$ on the rainfastness of $G P$}

A tank mix with adjuvant A-134 enhanced the rain-scouring tolerance of GP for controlling crabgrass and barnyard grass. Rainfall could reduce the control efficacy of GP, and the waning reduction was positively dependent on the increasing concentration of A-134 (Figure 2). The presence of $0.2 \%$ (v/v) A-134 maintained the lowest reduction at about $14.1 \%$ on the control efficacy of $50 \mathrm{~g}$ a.i./ha GP against crabgrass (Figure $2 \mathrm{a}$ ) and $11.5 \%$ on the control efficacy of $22.5 \mathrm{~g}$ a.i./ha GP against barnyard grass (Figure $2 \mathrm{~b})(p<0.05)$.

\section{Mechanism study}

2.1. Influence of A-134 on the surface tension and spreading area of $R D P$

Adjuvant A-134 significantly decreased the surface tension and increased the spreading area of RDP in a concentrationdependent manner (Figure 3). After tank mixing with $0.2 \%$ $(\mathrm{v} / \mathrm{v})$ A-134, the surface tension of RDP at a concentration of $4000 \mathrm{mg} / \mathrm{L}$ was changed to approximately $75.42 \%$ of the control, and the spreading area of RDP was about 1.40 times greater than that of the control.

\subsection{Influence of $A-134$ on glyphosate uptake}

After mixing with A-134, the uptake of glyphosate through the surface of crabgrass leaves was significantly increased as compared to that of the control (Figure 4). After a drop of $10 \mu \mathrm{L}$ RDP mixed with $0.1 \%$ A-134 was placed on crabgrass leaves for $10 \mathrm{~min}$, the remaining concentration of glyphosate on the crabgrass leaves was decreased from an initial 42.07 to $8.06 \%$, while the control was decreased from an initial 40.28 to $20.74 \%$. The rates of glyphosate uptake were increased 1.74 times by $0.1 \%$ (v/v) A-134 as compared with those of the control. Data suggested that tank mixing with A-134 caused faster penetration and improved uptake of glyphosate into the crabgrass as compared to those of RDP alone.

\section{Discussion}

Herbicides are almost always applied as formulated products. ${ }^{1)}$ Optimized herbicide formulations should possess the preferred properties for enhancing dispersion in water, increasing coverage and absorption by plants, decreasing the time required to control weeds, and ensuring safety of herbicides to humans and animals. $^{2,15)}$ The use of spray-tank adjuvants that increase droplet adhesion, retention, spreading, deposit formation, uptake, and translocation improves the efficacy of herbicides. ${ }^{4,9)}$ In order to improve the safe usage and efficiency of glyphosate, many innovative biogenic adjuvants that possess environmental compatibility, low aquatic toxicity, and easy biodegradation have been developed, such as alkyl polyglycosides, quaternary ammonium

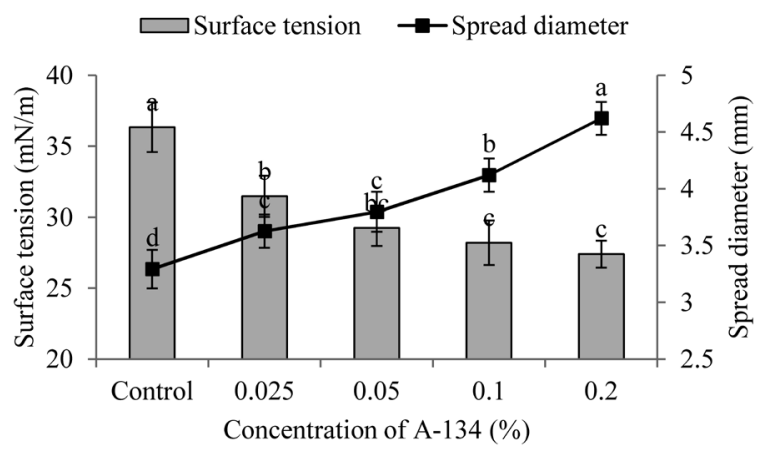

Fig. 3. Surface tension and spread diameter of $4000 \mathrm{mg} / \mathrm{L}$ RDP after tank mixing with $\mathrm{KAO}^{\circledR}$ adjuvant A-134. Data were statistical values of 2 sets with 3 parallel replicates and expressed as means plus SE. Means followed by the same asterisk on the same panel were not significantly different $(p<0.05$, LSD test). 


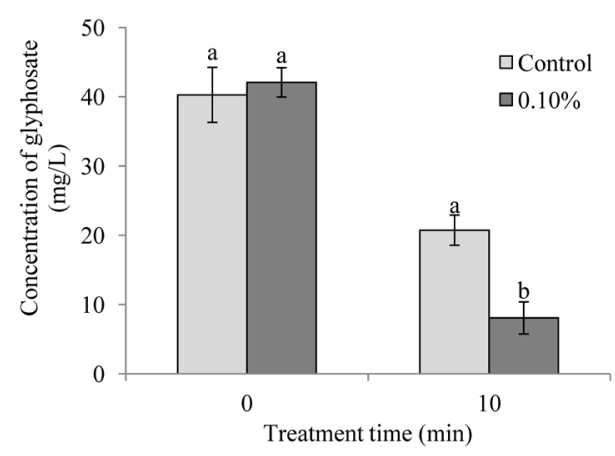

Fig. 4. Adjuvant effect of $0.1 \%(\mathrm{v} / \mathrm{v})$ A-134 on glyphosate uptake of $4000 \mathrm{mg} / \mathrm{L}$ RDP into the crabgrass leaves. The same volume of distilled water as for A-134 was used as the control. Data were statistical values of 2 sets with 3 parallel replicates and expressed as means plus SE. Means followed by the same asterisk on the same panel were not significantly different $(p<0.05$, LSD test).

glycosides, esterified polyoxyethylene glycerols, citric acid alkylether esters, and methylated polyoxyethylene fatty acids. ${ }^{16-19)}$ These adjuvants have been expected to replace the currently widely used nonylphenol polyoxyethylene and fatty amine polyoxyethylene that harm the environment. ${ }^{10)}$ The present study explores KAO adjuvant A-134, a new alkyl ether obtained from coconut oil. As compared with other conventional organic adjuvants (HM 9110, HM 9120A, Agrimax 3, Agrimax 5, and X-77, all 5\%) and alkylpolysaccharide adjuvants (LI 144, 2.5\%; LI 700, 5\%; ADE 702, 2.2\%; ADE 804, 6.6\%), the effective concentration of KAO A-134 is lower (the recommended amount is $0.1-0.2 \%){ }^{20,21)} \mathrm{A}-134$ significantly increased glyphosate activity through mechanisms such as a concentration-dependent decrease in the toxicity of RDP, a significant decrease in surface tension, and an increase in the spreading area.

The toxicity of glyphosate on mammals has been a concern worldwide. ${ }^{22)}$ Glyphosate-based herbicides are toxic endocrine disruptors in human cell lines. ${ }^{23)}$ Glyphosate induces the growth of human breast cancer cells via estrogen receptors, causes necrosis and apoptosis in mature rat testicular cells in vitro, and decreases testosterone at lower levels. ${ }^{24,25)}$ Moreover, long-term exposure to herbicides imposes a strong selection that enables weeds to produce resistance that must be minimized or it becomes a major limiting factor to food security in global agriculture. ${ }^{26)}$ In the present study, A-134 significantly induced faster penetration and improved uptake of glyphosate into crabgrass. This property may reduce the dose of glyphosate and shorten the exposure time of glyphosate in the environment, humans, and other non-target organisms, even as it significantly increases the control efficacy of glyphosate.

Weather conditions, specifically precipitation before and after herbicide application, can significantly impact herbicide efficacy, making it necessary for the herbicide to penetrate weeds rapidly and providing suitable rainfastness for adequate weed control. ${ }^{27)}$ Glyphosate herbicide lacks residual control, and, depending on the formulation, its efficacy can be reduced by precipitation after application. ${ }^{28)}$ Improved uptake and in-transport applications of glyphosate, however, are effective at controlling late-emerging weeds. ${ }^{29)}$ In the present study, A-134 increased droplet adhesion and concentration-dependently prevented the decline of the control efficacy of GP against crabgrass and barnyard grass after rain-scouring treatment. Whether the application of A-134 is beneficial for glyphosate transformation in weeds is worthy of further investigation.

In conclusion, the control efficacy of glyphosate after tank mixing with KAO adjuvant A-134 was significantly improved against crabgrass and barnyard grass, and the same synergies are seen in the field study. This tank-mixing adjuvant also increases glyphosate rainfastness and reduces the dosage of glyphosate needed to achieve satisfactory efficacy, especially enhancing the application performance and decreasing the cost and environment selective pressure.

\section{Acknowledgements}

The authors thank Tanaka Shingo and Tan Yong Kang (Kao Chemical Corporation Shanghai) for their valuable helps in providing the adjuvant. We are also grateful to the staff at herbicidal activity screening group for their kind assistances and providing the seeds of weeds in this study. This work was financial supported by National Key Technology Research Development Program of China (NO. 2017YFD0201107-2-2) and Innovation Program of Shanghai Municipal Education Commission (NO.201701070002E00037).

\section{References}

1) M. R. Uddin, S. U. Park, F. E. Dayan and I. Y. Pyon: Pest Manag. Sci. 70, 252-257 (2014).

2) H. M. G. V. D. Werf: Agric. Ecosyst. Environ. 60, 81-96 (1996).

3) M. Kucharski, J. Sadowski, B. Wujek and J. Trajdos: Prog. Plant Prot. 47, 1868-1874 (2009).

4) S. D. Sharma, R. C. Kirkwood and T. L. Whateley: Weed Res. 36, 227239 (1996).

5) P. Devkota, J. K. Norsworthy and R. Rainey: Weed Technol. 29, 284297 (2015).

6) R. D. Buick, G. D. Buchan and R. J. Field: Pest Manag. Sci. 38, 227235 (1993).

7) P. J. G. Stevens, M. O. Kimberley, D. S. Murphy and G. A. Policello: Pest Manag. Sci. 38, 237-245 (1993).

8) D. Martins, C. A. Carbonari, M. A. Terra and S. R. Marchi: Planta Daninha 27, 155-163 (2009).

9) Z. Q. Liu and J. A. Zabkiewicz: N. Z. Plant Prot. 52, 228-233 (1999).

10) J. M. Brausch and P. N. Smith: Arch. Environ. Contam. Toxicol. 52, 217-221 (2007).

11) J. Li, W. G. Johnson and R. J. Smeda: Crop Prot. 21, 1087-1092 (2002).

12) B. G. Young and J. M. Young: J. ASTM Int. 2, 7 (2005).

13) D. Chikoye, A. F. Lum and U. F. Udensi: Crop Prot. 29, 947-952 (2010).

14) J. Soukup, M. Jursík, P. Hamouz, J. Holec and J. Krupka: Plant Soil Environ. 50, 88-94 (2004).

15) L. Kong, J. Zhang, H. Jiang, L. Cao, L. I. Fengmin and Q. Huang: Chin. J. Pestic. Sci. 14, 83-88 (2012).

16) F. Cabanne: Weed Res. 40, 181-189 (2000).

17) A. K. Underwood: Weed Technol. 14, 765-772 (2009). 
18) B. Gustavsson: Eur. Pat. Appl. EP 1154687, B1 (2003).

19) J. L. Hazen and Y. B. Lei: Proc. Am. Soc. Test. Mater. 1430, 54-65 (2003).

20) D. Singh and M. Singh: Weed Biol. Manage. 8, 104-111 (2008).

21) J. Menendez, D. Camacho, M. C. Fernandez-Cerejido and F. Bastida: Weed Res. 51, 344-352 (2011).

22) S. M. Bradberry, A. T. Proudfoot and J. A. Vale: Toxicol. Rev. 23, 159167 (2004).

23) C. Gasnier, C. N. Dumont, N. Benachour, E. Clair, M. C. Chagnon and G. E. Séralini: Toxicology 262, 184-191 (2009).

24) É. Clair, R. Mesnage, C. Travert and G. É. Séralini: Toxicol. In Vitro 26, 269-279 (2012).
25) S. Thongprakaisang, A. Thiantanawat, N. Rangkadilok, T. Suriyo and J. Satayavivad: Food Cosmet. Toxicol. 59, 129-136 (2013).

26) R. Busi, M. M. Vilaaiub, H. J. Beckie, T. A. Gaines, D. E. Goggin, S. S. Kaundun, M. Lacoste, P. Neve, S. J. Nissen, J. K. Norsworthy, M. Renton, D. L. Shaner, P. J. Tranel, T. Wright, Q. Yu and S. B. Powles: Evol. Appl. 6, 1218-1221 (2013).

27) C. L. Stewart, N. Soltani, R. E. Nurse, A. S. Hamill and P. H. Sikkema: Am. J. Plant Sci. 3, 1193-1204 (2012).

28) E. C. Sivesind, J. M. Gaska, M. R. Jeschke, C. M. Boerboom and D. E. Stoltenberg: Weed Technol. 25, 44-50 (2013).

29) R. E. Nurse, C. J. Swanton, F. Tardif and P. H. Sikkema: Crop Prot. 25, 1174-1179 (2006). 